\title{
MECHANISMS OF POLYMER STABILIZATION
}

\author{
G. ScotT \\ Department of Chemistry \\ University of Aston in Birmingham, Warwickshire, UK
}

\begin{abstract}
The behaviour of antioxidant in polymers differs markedly depending on the type of test used. The performance of antioxidants can be optimized on the basis of intrinsic activity, compatibility with the polymer and rate of loss from the polymer by volatilization. Molecular interactions in antioxidants and stabilizers have a profound effect on all these factors which may be influenced in opposite directions. Present trends in antioxidant and stabilizer technology are toward agents designated to meet specific requirements. The progress of recent studies on the mechanism of sulphide and phosphite antioxidants is reviewed.
\end{abstract}

\section{INTRODUCTION}

Industrial companies spend many hundreds of thousands of pounds a year on the evaluation of new stabilizing systems for polymers. Much of this testing is carried out under conditions which bear little relation to practical performance and considerable doubt exists about the ability of accelerated tests to predict correctly the useful service life of the fabricated article. Three types of prediction test can be distinguished.

\section{(a) Melt stability tests}

The evaluation of polymer melt stability by the measurement of changes in meit viscosity has direct relevance to the performance of the polymer under processing conditions. The effect of the stabilizer in this case is to extend the induction period to rapid viscosity change and this is normally carried out by monitoring changes in melt-flow index at intervals during the processing operation ${ }^{1}$ or by continual measurement of polymer viscosity in a torque rheometer under oxidative conditions ${ }^{2}$. Assuming that this type of test is carried out under the same conditions of temperature, shear and environment then results are directly relevant to engineering practice. Apart from noting at this stage that what happens to the polymer under these conditions determines the subsequent performance of polymer articles under service conditions ${ }^{3}$, this type of test is the most satisfactory predictor of performance of those normally used and will not be discussed further. 


\section{(b) Thermal stability of fabricated test pieces}

The second type of test which is widely used as a predictor of long term performance involves high temperature evaluation of fabricated component performance. This is normally carried out by subjecting sheet or film to temperatures between $100^{\circ}$ and $150^{\circ} \mathrm{C}$ in an oxygen or air stream ${ }^{4-8}$. This type of evaluation, which is used almost universally by polymer and stabilizer manufacturers is open to the severe criticism that these conditions bear little relationship to those encountered in the normal service life of polymers. The exceptions to this are polymers used in hot water systems or in engineering components where high temperature is one of the conditions of service. For ambient use, the amounts of antioxidant incorporated to stabilize the polymer in the melt are normally more than adequate to protect the polymer during service. The amount of antioxidant used to give polypropylene adequate processing stability at $200^{\circ}$ can be calculated (assuming the Arrhenius relationship holds) to give the fabricated article a service life of between ten and twenty years if environmental degradation occurs simply as a result of thermal reactions. In practice service behaviour is much more complex than this and factors other than thermal oxidation become dominating. In plastics by far the most important of these is u.v. light.

\section{(c) The u.v. and simulated weathering stability of fabricated test pieces}

The u.v. exposure cabinet test is much more relevant to the service life of the polymer than is the high temperature thermal stability test, assuming an u.v. source has been selected to provide a similar spectral distribution to that of sunlight. Accelerated u.v. testing also has the advantage that it can be correlated directly with outdoor exposure. Moreover, lifetime extrapolation can be made directly to service conditions based on previous experience of the u.v. source. Since other speakers at this conference will be discussing u.v. stabilization, this type of technique will not be discussed further in this lecture.

\section{ANTIOXIDANT ENVIRONMENT IN THE POLYMER}

In spite of the practical lack of relevance of the thermal stability test (b) as a direct predictor of service life for most applications, it is still widely used in industry. Recent work has thrown a good deal of light on the factors which determine stabilizer activity under practical conditions. It has been known for some time as a result of experience in rubber and more recently polypropylene that a factor of major importance in determining antioxidant activity is the molecular weight of the antioxidant ${ }^{9}$.

The work of Gordon ${ }^{10}$ is particularly illuminating in this connection, since he has shown that the way in which an antioxidant is tested determines its relative effectiveness in relation to other antioxidants. Table 1 shows that antioxidants rate in effectiveness in different orders depending on the sample thickness in an even test at $125^{\circ} \mathrm{C}$.

First of all, it should be noted that all antioxidants become apparently more effective as the sample thickness is increased but that some (e.g. antioxidants $A$ and $D$ ) show this effect much more markedly than others (e.g. antioxidant I). 


\section{MECHANISMS OF POLYMER STABILIZATION}

Table 1. Days to failure in oven ageing at $125^{\circ} \mathrm{C}$.

\begin{tabular}{|c|c|c|c|}
\hline \multicolumn{4}{|c|}{ Sample thickness, $\mathrm{cm}^{-2}$} \\
\hline 2.5 & 25 & 60 & 120 \\
\hline A22 & B117 & B151 & B166 \\
\hline B29 & A130 & C185 & $\mathrm{C} 219$ \\
\hline $\mathrm{C} 34$ & $\mathrm{C} 140$ & $\mathrm{~A} 240$ & E368 \\
\hline E34 & E187 & E287 & \begin{tabular}{|l|}
$\mathrm{A} 390$ \\
\end{tabular} \\
\hline H34 & F226 & F375 & F453 \\
\hline D50 & D256 & 1418 & 1501 \\
\hline F50 & G259 & $\mathrm{G} 460$ & $G>600$ \\
\hline G75 & 1288 & D479 & $\mathrm{D}>600$ \\
\hline 195 & $\mathrm{H} 297$ & $\mathrm{H} 552$ & $\mathrm{H}>600$ \\
\hline
\end{tabular}

A similar pattern emerges if the sample thickness is held constant but the temperature of testing is increased (Table 2).

Table 2. Days to failure in oven ageing tests for $25 \mathrm{~cm}^{-2}$ samples.

\begin{tabular}{cccc}
\hline \multicolumn{4}{c}{ Temperature, ${ }^{\circ} \mathrm{C}$} \\
100 & 125 & 140 & 150 \\
\hline B167 & B117 & A22 & A9 \\
C183 & A130 & B34 & B15 \\
\hline A286 & C140 & C35 & D15 \\
\hline E300 & E187 & D53 & C17 \\
G387 & F226 & E57 & H19 \\
H466 & D256 & F64 & F27 \\
\hdashline i507 & G259 & G66 & G30 \\
\hdashline F $>600$ & I288 & H72 & E31 \\
D $>600$ & H297 & I174 & I33 \\
\hline
\end{tabular}

Here again all antioxidants decrease in effectiveness with increasing temperature but some (e.g. antioxidants A and D) are much more susceptible to temperature increase than are others (e.g. antioxidant I) and their relative ratings as the temperature is increased are quite different. It is clear then that factors other than inherent antioxidant efticiency are playing a part and the obvious inference to be drawn from Tables 1 and 2 is that antioxidants $A$ and $D$ are relatively volatile antioxidants whereas antioxidant $I$ is relatively involatile.

We have carried out a more systematic study of the effect of antioxidant molecular weight and volatility in two series of antioxidants. each of which contained the same antioxidant function (Table 3$)^{11}$. 


\section{G. SCOTT}

Table 3. Induction periods of two series of isofunctional antioxidants in decalin.

\begin{tabular}{|c|c|c|c|c|}
\hline Antioxidant function & $\begin{array}{c}\text { Side } \\
\text { chain } \\
\text { R }\end{array}$ & $\underset{{ }^{\circ} \mathrm{C}}{\mathrm{M} . \mathrm{pt}}$ & $\begin{array}{c}\text { Mol. } \\
\text { wt }\end{array}$ & $\begin{array}{l}\text { Induction period } \\
\mathrm{h}\end{array}$ \\
\hline$\left(\mathrm{ROCOCH}_{2} \mathrm{CH}_{2}\right)_{2} \mathrm{~S}$ & $\begin{array}{l}\text { Methyl } \\
\text { Hexyl } \\
\text { Lauryl } \\
\text { Stearyl }\end{array}$ & $\begin{array}{l}\overline{-} \\
41.2 \\
57.8\end{array}$ & $\begin{array}{l}206 \\
346 \\
514 \\
702\end{array}$ & $\left.\begin{array}{l}28 \\
27 \\
26 \\
26\end{array}\right\} 2 \times 10^{-5}$ mole $/ 100 \mathrm{~g}$ \\
\hline$\sum_{t-\mathrm{Bu}}^{t-\mathrm{Bu}}-\mathrm{CH}_{2} \mathrm{CH}_{2} \mathrm{COOR}$ & $\begin{array}{l}\text { Methyl } \\
\text { Hexyl } \\
\text { Lauryl } \\
\text { Stearyl }\end{array}$ & $\begin{array}{l}67.8 \\
10 \\
15 \\
51.2\end{array}$ & $\begin{array}{l}292 \\
362 \\
446 \\
530\end{array}$ & $\left.\begin{array}{l}27 \\
24 \\
22 \\
18\end{array}\right\} 2 \times 10^{-3} \mathrm{~mole} / 100 \mathrm{~g}$ \\
\hline
\end{tabular}

Members of both these series give a slightly decreasing antioxidant activity on a molar basis when measured in a sealed system by oxygen absorption. Behaviour in polypropylene in a sealed system is rather different in that there is maximum effectiveness with the lauryl ester in the case of the phenols (see Figure 1). There is an interesting inverse correlation with melting point suggesting that under these conditions compatibility with the polymer is playing a role in antioxidant effectiveness.

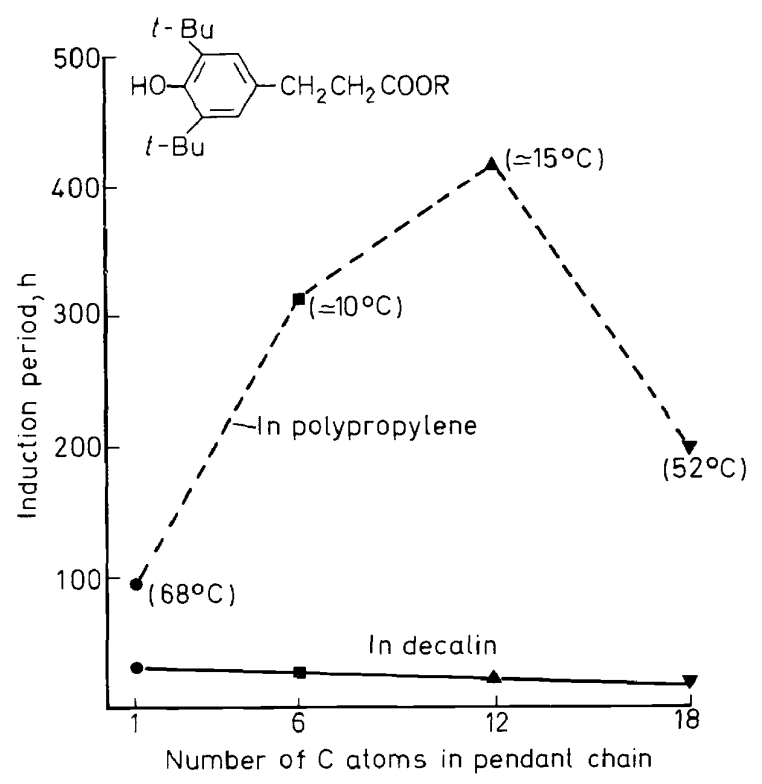

Figure 1. Effect of sidechain length on the effectiveness of the isofunctional phenolic antioxidants at $140^{\circ} \mathrm{C}$ by oxygen absorption. 


\section{MECHANISMS OF POLYMER STABILIZATION}

It can be seen (see Table 3) that the sulphur series is very much more effective than the phenol series. It has been suggested earlier ${ }^{12.13}$ that sulphur dioxide, which is known to be formed from the thiodipropionate esters by reaction with hydroperoxides and which is a very efficient catalyst for hydroperoxide decomposition ${ }^{14}$, is one of the compounds which contribute to the powerful antioxidant activity of this class of antioxidant. Some weight is given to this by the finding that in a closed system and at the same molar concentration, sulphur dioxide is about as effective as the thiodipropionates. However, other lower molecular weight species derived from the thiodipropionate esters by oxidation are also formed which effect the same acid-catalysed process ${ }^{15}$.

Oxygen absorption tests give valuable information about inherent antioxidant activity but predict little of practical value about behaviour under service conditions. In addition results from the plaque oven ageing test referred to earlier are notoriously irreproducible. The reasons for this are associated with the difficulty in assuring that each sample is identical with respect to dimensions, prior heat treatment, antioxidant dispersion, etc. and an accuracy better than \pm 50 per cent is not normally possible.

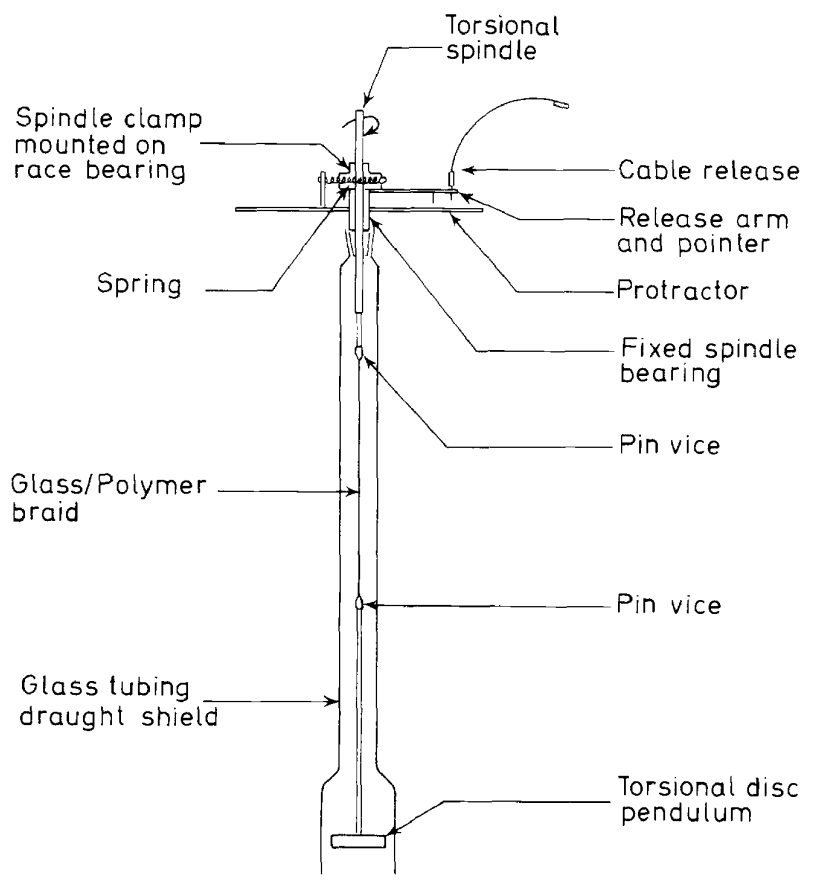

Figure 2. Apparatus for determination of torsional period of braids. 


\section{G. SCOTT}

In our own work considerable attention was paid to these factors. The technique used was a modification of that used by Lewis and Gillham ${ }^{16,17}$ for following crosslinking reactions in polymers. The test piece was a glasspolymer braid, whose torsional period was measured (see Figure 2) at intervals on ageing in a single-cell oven at temperatures between $100^{\circ} \mathrm{C}$ and $140^{\circ} \mathrm{C}$ with a constant flow of oxygen past the sample (28.3 1./h). Particular care was taken that the samples were reproducible. Unstabilized polypropylene was used in all experiments and stabilizers were incorporated at concentrations between $2 \times 10^{-4}$ and $2 \times 10^{-2} \mathrm{~mol} / 100 \mathrm{~g}$ by solvent application and evaporation. This technique was found to give more reproducible results than ball-milling of the antioxidant and polypropylene powder. The polypropylene was applied to the glass (which was carefully heat treated at $400^{\circ} \mathrm{C}$ for two hours to remove the size) by wetting the glass with distilled water and drawing through the powder. Fusion was carried out in the complete absence of oxygen by heating to $200^{\circ} \mathrm{C}$ in nitrogen after first displacing air from the polypropylene powder ${ }^{11}$. After one fusion cycle, the melting point of the polymer was found to be constant indicating satisfactory antioxidant dispersion.

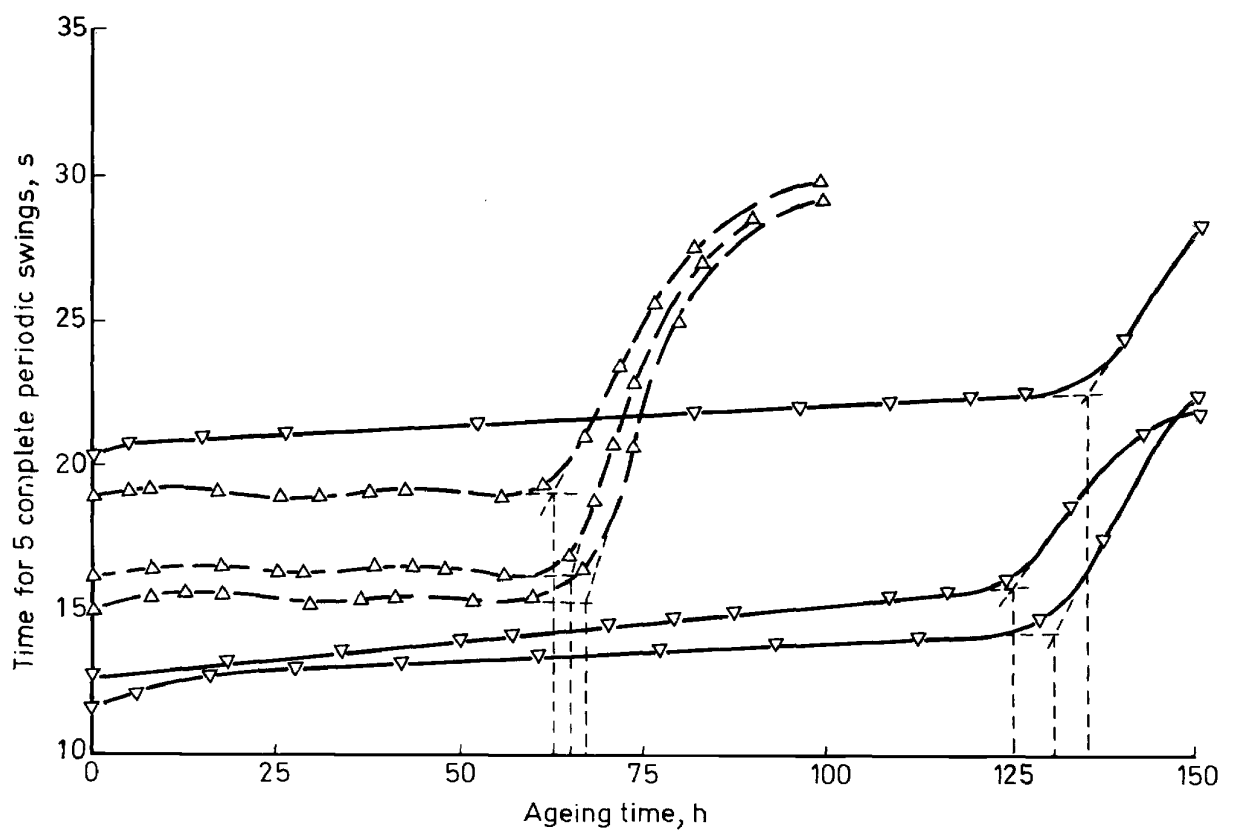

Figure 3. Typical polypropylene torsion braid decay curves at $100^{\circ} \mathrm{C}:-\nabla-$ dilauryl thiodipropionate; $-\Delta$-lauryl- $\beta$-(3,5-di-tert-butyl-4-hydroxy phenyl)-propionate. Antioxidant concentration $2 \times 10^{-+}$moles $/ 100 \mathrm{~g}$ polymer.

The polymer-glass braids produced by the above procedure were found to be remarkably consistent. The polypropylene content of the braids was $52 \pm 2$ per cent and the radius $0.3 \pm 0.03 \mathrm{~mm}$. It was found that the end of 
the induction period, as indicated by a rapid increase in the torsional period of the braid, was consistent to \pm 10 per cent (see Figure 3 ) and although the initial modulus of the braids varied, this did not seem to affect the accuracy of the result.

As anticipated, under the conditions outlined involving high surface area to volume ratio and continual change in atmosphere, the effectiveness of antioxidants in the same homologous series varied markedly with molecular weight. The results obtained at $100^{\circ} \mathrm{C}$ at two molar concentrations are shown in Table 4.

Table 4. Effect of molecular weight on the induction period of two series of antioxidants.

\begin{tabular}{|c|c|c|c|c|}
\hline Antioxidant & $\mathbf{R}$ & $\begin{array}{c}\text { Mol. } \\
\text { wt }\end{array}$ & $\begin{array}{l}\text { Induction } \\
2 \times 10^{-4} \\
\mathrm{~mol} / 100 \mathrm{~g}\end{array}$ & $\begin{array}{l}\text { period, } \mathrm{h} \\
2 \times 10^{-3} \\
\mathrm{~mol} / 100 \mathrm{~g}\end{array}$ \\
\hline \multirow[t]{2}{*}{$\left(\mathrm{ROCOCH}_{2} \mathrm{CH}_{2}\right)_{2} \mathrm{~S}$} & Methyl & 206 & 25 & 42 \\
\hline & Hexyl & 346 & 30 & 42 \\
\hline \multirow{2}{*}{$t-\mathrm{Bu}$} & Lauryl & 514 & 65 & 80 \\
\hline & Stearyl & 702 & 130 & 430 \\
\hline \multirow[t]{4}{*}{$\mathrm{HO}-\left(-\mathrm{CH}_{2} \mathrm{CH}\right.$} & Methyl & 292 & 25 & 45 \\
\hline & Hexyl & 362 & 40 & 80 \\
\hline & Lauryl & 446 & 75 & 400 \\
\hline & Stearyl & 530 & 9800 & $\gg 10^{4}$ \\
\hline
\end{tabular}

A simple volatility cell was used to measure the relative volatility of antioxidants at various temperatures in an atmosphere of nitrogen to eliminate the possibility of antioxidant destruction by oxygen. A plot of $\log$ IP against the reciprocal of the volatility $(1 / V)$ showed (see Figure 4$)$ that the two series of antioxidants differed very considerably in their efficiency/ volatility relationship: the phenol series is very much more effective than the sulphides as volatility is reduced. The reason for this is almost certainly associated with the fact that in performing an antioxidant function, thiodipropionate esters break down to lower molecular weight fragments which will be more readily lost from the polymer (see later). The results also explain why the higher molecular weight antioxidants discussed above are so much more effective than dilauryl thiodipropionate and do not show very marked synergism with it under high temperature test conditions ${ }^{18}$.

There appears to be a superimposed factor which introduces a limit to the effectiveness/inverse volatility relationship. Figure 4 shows that the pentaerythritol-based antioxidant containing the same functional group is less effective on a molar basis than might have been expected on the basis of its $1 / V$ value. This appears to be associated with compatibility/mobility factors in the polymer. The melting point of this antioxidant $\left(120^{\circ} \mathrm{C}\right)$ is 


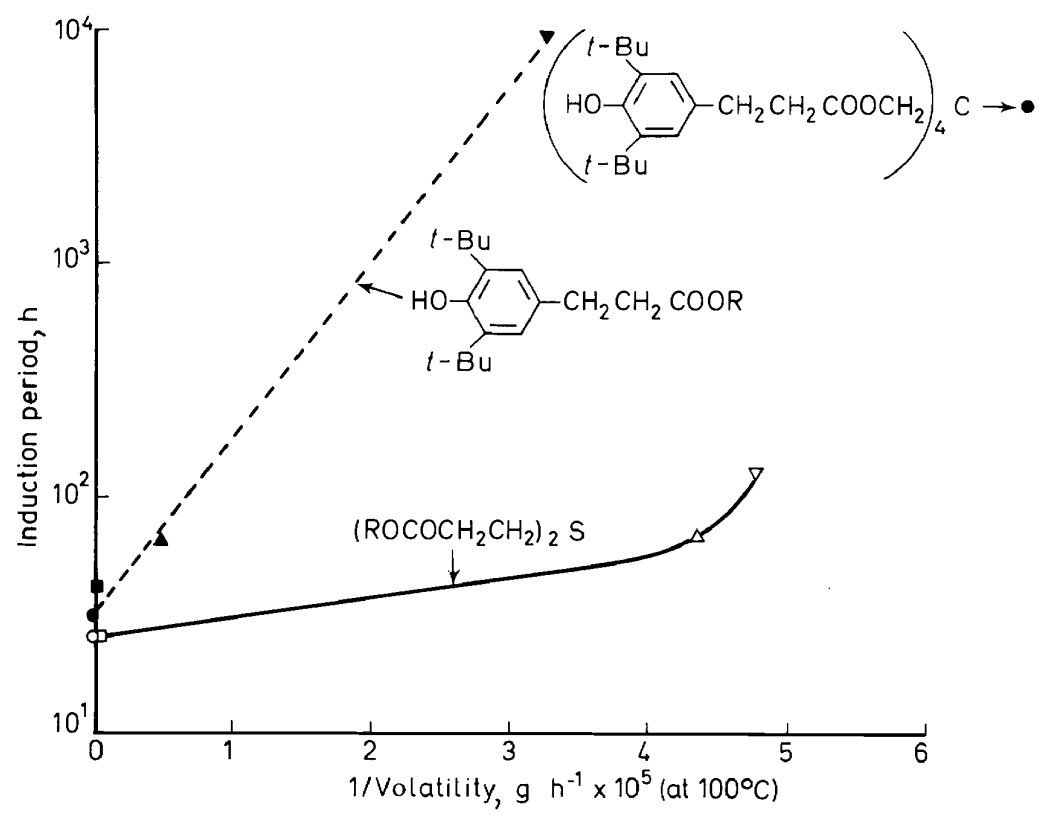

Figure 4. Effect of sidechain length on the effectiveness of isofunctional antioxidants at $100^{\circ} \mathrm{C}$ by torsion braid.

considerably higher than those of the others studied implying limited compatibility in the polymer. DTA studies have shown that unlike the other propionic ester-based phenols, this antioxidant has almost no effect on the melting point of the polymer, confirming its incompatibility.

The importance of factors other than molecular weight has been observed in a similar study of increasing molecular weight in the series ${ }^{19}$<smiles>Cc1cc(C)c(O)c(CCc2cc(C)cc(CCc3cc(C)cc(C)c3O)c2O)c1</smiles>
where $n=0$ to 3

These antioxidants were compared on a molar basis (i.e. mole/100 g polymer of functional group) in the three tests discussed, namely decalin in oxygen absorption at $140^{\circ} \mathrm{C}$, polypropylene in oxygen absorption at $140^{\circ} \mathrm{C}$ and polypropylene by torsional braid at $140^{\circ} \mathrm{C}$. Figure 5 shows a pronounced alternation with the value of $n$ but the alternation is in opposite directions depending on the type of test used. In oxygen absorption in decalin there is a general trend toward decreased activity with increasing molecular weight, 


\section{Induction periods, $h$}

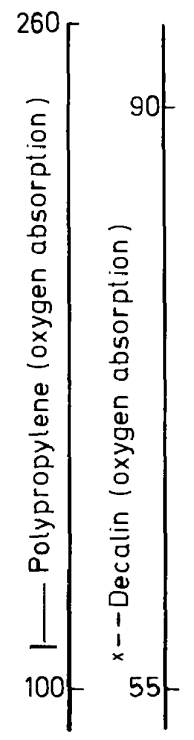

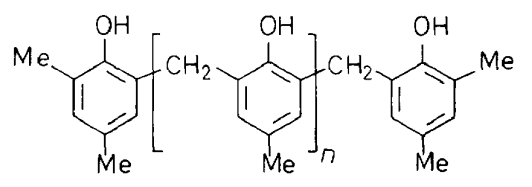

in polypropylene

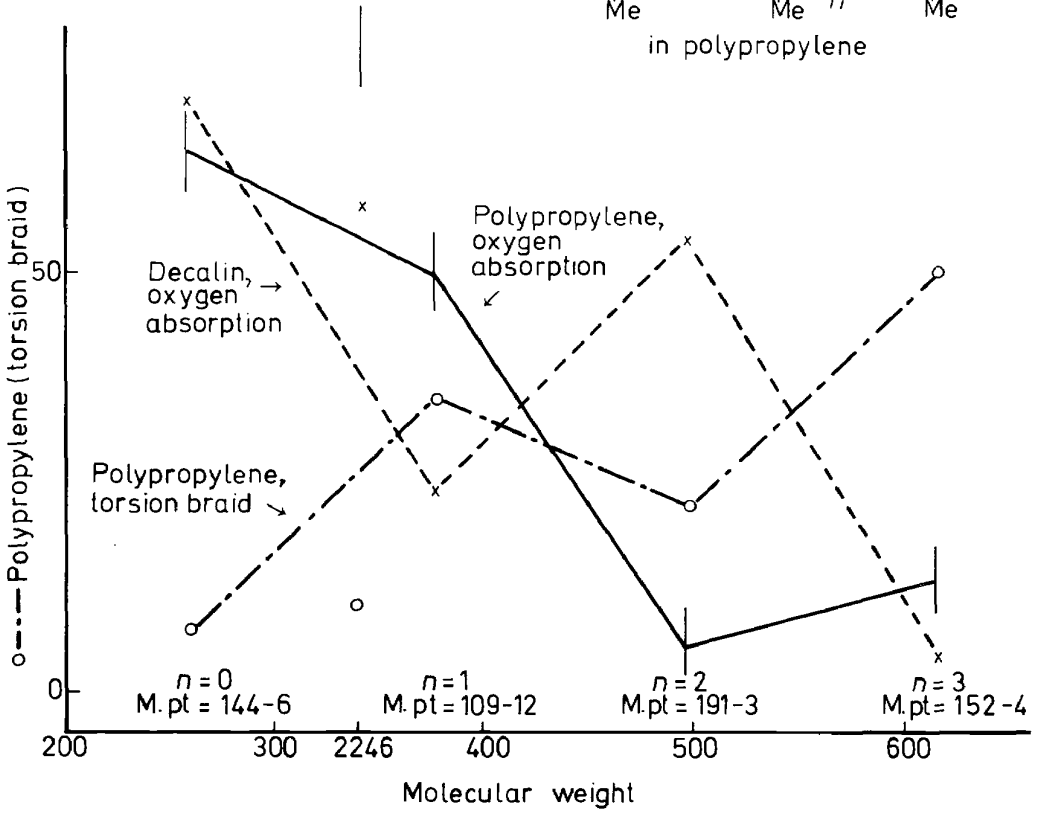

Figure 5. Antioxidant activity at $140^{\circ} \mathrm{C}$ of polyphenols.

but antioxidants having $n=0$ or 2 are more effective than those having $n=1$ or 3 . In the torsion braid test there is a general increase in effectiveness but $n=0$ or 2 are less effective than $n=1$ or 3 . In the oxygen absorption test in the polymer there is a more marked decrease in activity with $n=0$ or 2 being less effective than $n=1$ or 3 . It seems likely that the alternating effects are all associated with intra- and inter-molecular associations. Intramolecular hydrogen bonds seem to increase the inherent antioxidant activity but this is associated with a decrease in intermolecular hydrogen bonding and hence increase in volatility. The overall effect is to reduce the effectiveness of the antioxidant in the torsion braid test. Internal hydrogen bonding also increases the melting point and hence decreases compatibility so that $n=0$ or 2 have higher melting points (see Table 5) and hence lower compatibilities than $n=1$ or 3 .

It is constructive to compare the position of a commercial bisphenol, Antioxidant 2246 in these three tests. Its intrinsic antioxidant activity and compatibility are good and it performs well in both the closed system tests. It is traditionally noted for its good performance in the 'oxygen bomb' test which is of this type. In the torsion braid test it is singularly ineffective, underlining the fact that volatility can dominate other factors in practical conditions. 


\section{G. SCOTT}

Table 5. Physical characteristics of polyphenolic antioxidants.

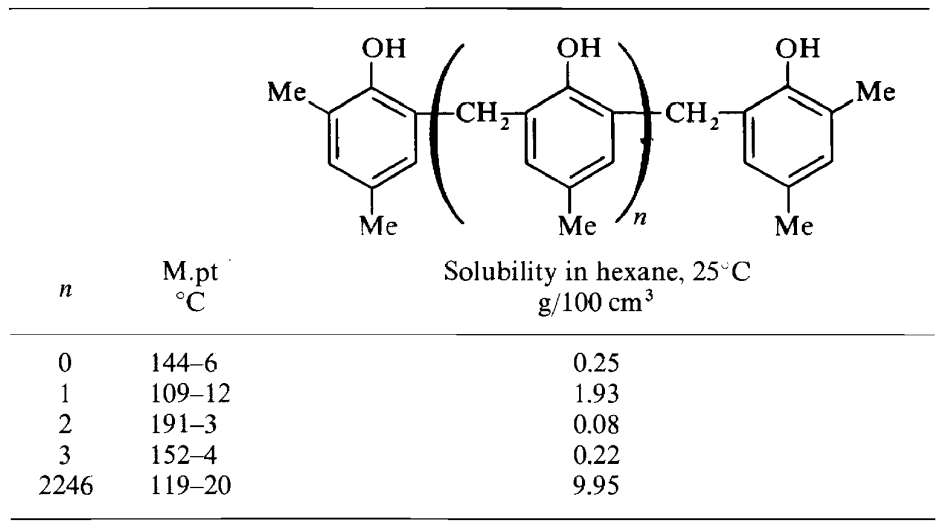

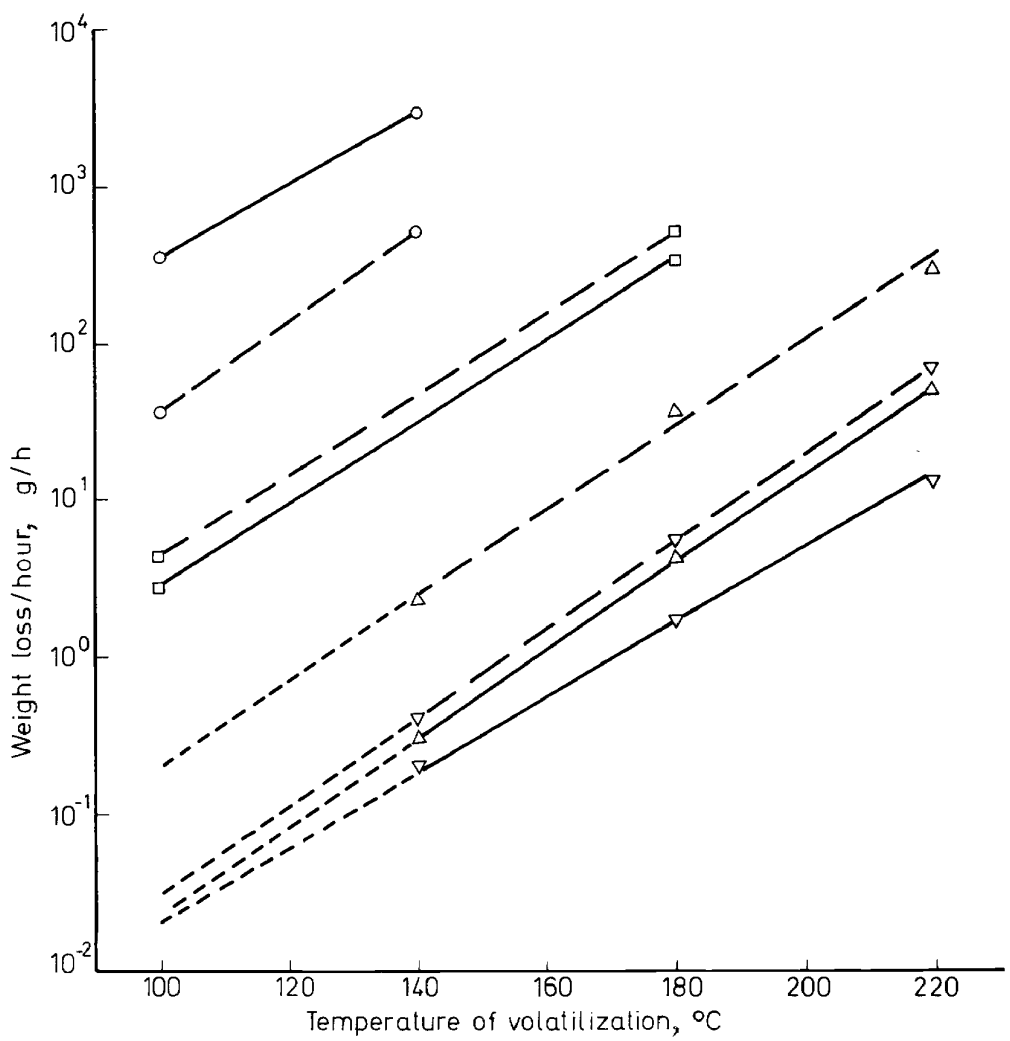

Figure 6. Relationship between temperature and volatility of antioxidants of various molecular weights. 
Summarizing then, three factors appear to be important in determining antioxidant activity and any of these might have a dominating influence depending on conditions of test. These are:

(a) Intrinsic antioxidant activity, which is influenced primarily by the structure of the molecule, including factors such as intramolecular interactions.

(b) Compatibility/mobility of the antioxidant which will again be determined by intra- and inter-molecular interactions in the molecule but generally in the opposite direction to the above.

(c) Volatility of the antioxidant which will be determined by molecular weight and molecular interaction in the polymer.

Although testing of the last factor has been largely carried out at $100^{\circ} \mathrm{C}$ and above, the results appear relevant to service performance since volatility/ temperature plots appear to be linear and generally parallel (see Figure 6). It seems likely therefore that in fabricated articles with a large surface area to volume ratio, persistence of antioxidants and stabilizers will be considerably more relevant to service performance than intrinsic antioxidant activity. Careful consideration must therefore be given to selecting the type of test which is most relevant to service performance.

\section{DESIGN OF ANTIOXIDANTS FOR HIGH TEMPERATURE, HIGH SURFACE AREA PERFORMANCE}

The future of antioxidants for this type of application lies therefore in the direction of increasing the retention of the antioxidant in the polymer. Interesting results have been reported by Phillips, Thomas and Wright ${ }^{20}$ for high temperature rubbers. By building a conventional antioxidant structure into a polymer chain, for example by reacting hydroquinone with $p$-phenylenediamine. an involatile antioxidant (I) was obtained which was much

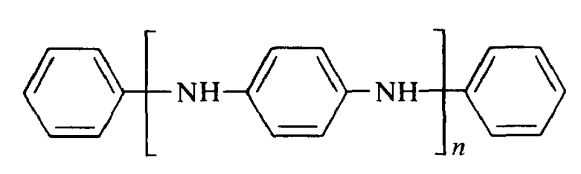

(I)

more effective in EPDM and Viton rubbers at $150^{\circ}$ and $250^{\circ} \mathrm{C}$ respectively than the conventional arylamine antioxidants normally used for high temperature applications.

The effect of molecular weight on rubber antioxidant performance has also been reported by Monsanto ${ }^{21}$ who have found that increasing the size of the $\mathrm{N}$-alkyl group (R) in the $p$-phenylenediamine antioxidants (II) considerably increases their antioxidant activity under practical conditions where extraction by water may be of importance. Figure 7 shows that Santofex IP (II, $\mathrm{R}=$ isopropyl) although initially more effective than 


\section{G. SCOTT}

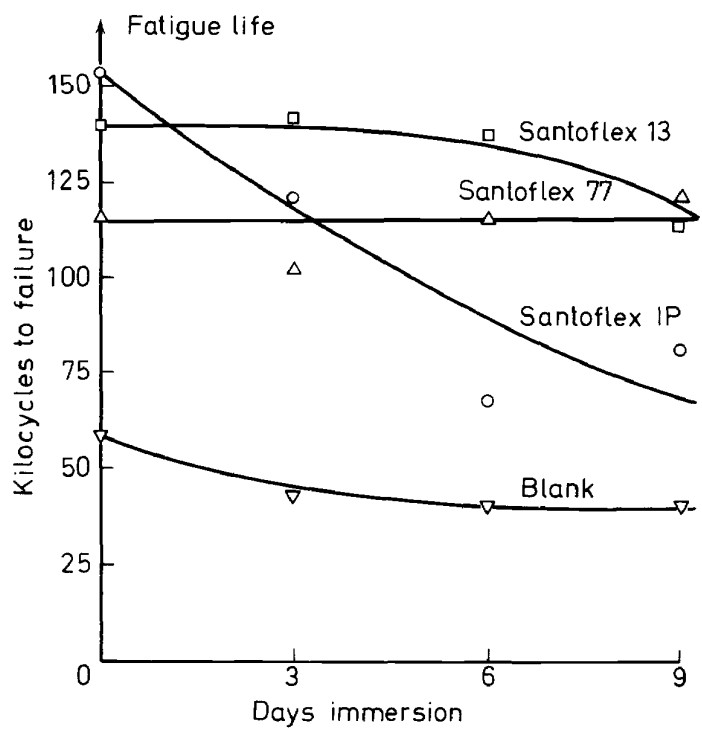

Figure 7. Effect of water extraction on the fatigue life of rubbers containing antioxidants.

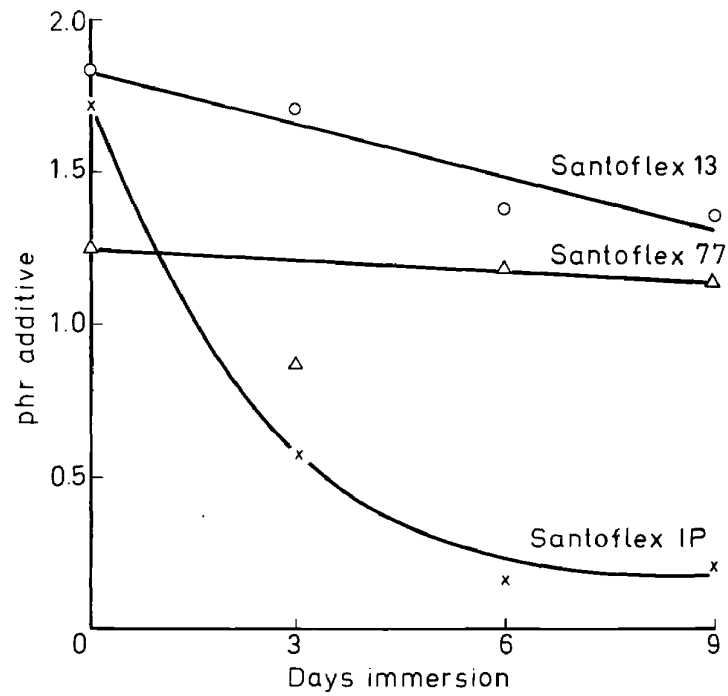

Figure 8. Effect of water extraction on the concentration of antioxidants in rubber. 


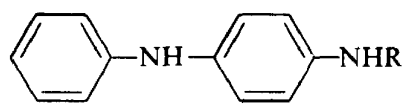

(II)

Santoflex 13 (II, $R=1,3$-dimethylbutyl) is much less effective after immersion in water. Figure 8 shows that this is due to more rapid extraction of the lower molecular weight antioxidant from the polymer.

An interesting approach to this same problem has been the development of rubbers with antioxidants chemically attached to the polymer chain. By reacting nitroso-containing antioxidants (e.g. diethylaminonitrosoaniline, DENA) with rubbers (a modification of the reaction involved in the crosslinking of rubber by dinitrosobenzene), Cain and his co-workers ${ }^{22}$ have found that the antioxidant can no longer be removed from the rubber by extraction with water at $100^{\circ} \mathrm{C}$.

(c)
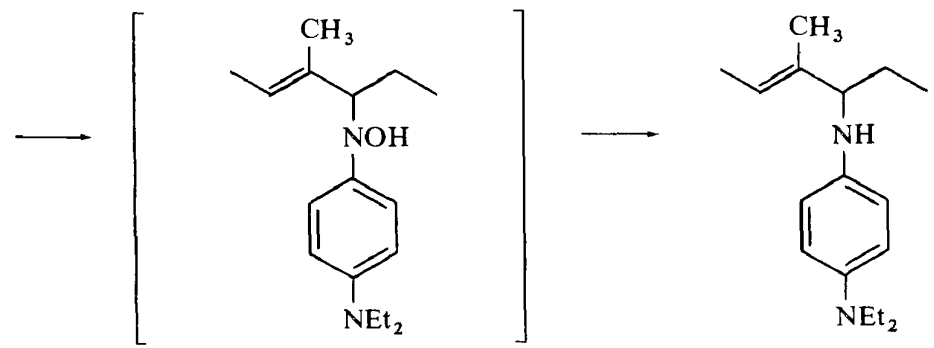

Table 6. Oxygen absorption at $100^{\circ} \mathrm{C}$ of water. Extracted vulcanizates (Cain et al.)

\begin{tabular}{|c|c|c|c|}
\hline \multirow{2}{*}{ Vulcanizate } & \multirow{2}{*}{ Additive } & \multicolumn{2}{|c|}{ Time to $1 \% \mathrm{w} / \mathrm{w}$ absorption, $\mathrm{h}$} \\
\hline & & Unextracted & Extracted \\
\hline CBS (white) & DENA & 39 & 33 \\
\hline CBS (black) & DENA & 30 & 32 \\
\hline CBS (white) & IPPD & 47 & 8 \\
\hline CBS (black) & IPPD & 40 & 18 \\
\hline
\end{tabular}

Here again, although the isopropyl compound (II, $\mathrm{R}=$ isopropyl) is more effective initially, the polymer-bound antioxidant persists in the rubber and is much more effective under conditions of extraction. 


\section{G. SCOTT}

\section{NEW DEVELOPMENTS IN ANTIOXIDANT MECHANISMS}

It seems likely that apart from the type of development discussed above, the future of antioxidants acting by the kinetic chain-breaking mechanism is somewhat limited ${ }^{23}$. This is primarily because the 2,6-di-tert-butyl phenol structure probably combines the best balance of properties for radical capture. Few improved commercial phenolic antioxidants have emerged in recent years and it seems likely that the future lies in the direction of further developments of synergistic systems involving phenols particularly for environmental stabilization. This will be increasingly important as bulk polymers are increasingly accepted in the building and automotive industries. In this connection the peroxide decomposers play a dual role since not only do they stabilize polymers during fabrication operations but they also act as powerful u.v. stabilizers due to their ability to remove the hydroperoxides on which u.v. light acts to produce a powerful photo-initiation of autoxidation $^{3}$.

Two main types of peroxide decomposer have achieved industrial importance in synergistic systems. The first is the sulphur-containing stabilizers of which the thiodipropionate esters (DLTP) (III), the zinc dialkyldithiocarbamates (IV) and a variety of thiols (V and VI) and related disulphides (VII) have become important particularly in thermal stabilization of polypropylene ${ }^{13}$.<smiles>[R10]C(=O)OCCCCCCCCC(=O)OCc1ccccc1</smiles>

(III)<smiles>Sc1nc2ccccc2[nH]1</smiles>

(V)<smiles>Sc1ccc2ccccc2c1</smiles>

(VI)

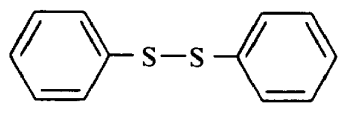

(VII)

The second is the phosphite esters (VIII)

$$
\begin{aligned}
& (\mathrm{RO})_{3} \mathrm{P} \text { where } \mathrm{R}=\text { alkyl, aryl and cycloaryl } \\
& \text { (VIII) }
\end{aligned}
$$

which are again effective as melt stabilizers particularly in combination with phenolic antioxidants with which they show pronounced concentration ratio optima ${ }^{24}$ as do the sulphur compounds ${ }^{9}$. It is of some interest that the peroxide decomposers which act as u.v. stabilizers react with hydroperoxides 


\section{MECHANISMS OF POLYMER STABILIZATION}

even at ambient temperatures. This is particularly true of the metal dialkyl dithiocarbamates and dithiophosphates which rapidly evolve sulphur dioxide and catalytically destroy hydroperoxides at room temperature ${ }^{14}$. and the trialkyl phosphites which are equally effective at $25^{\circ} \mathrm{C}^{25}$ but act stoichiometrically not catalytically.

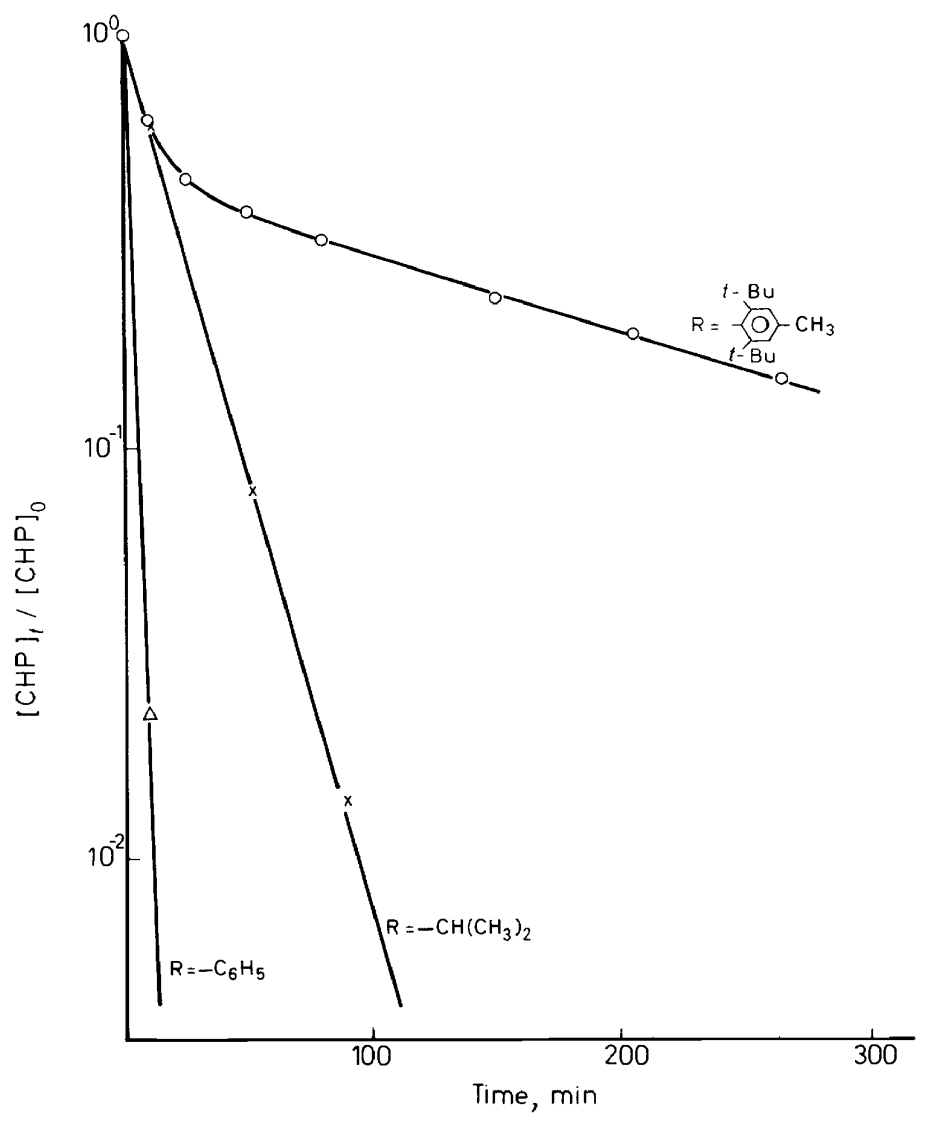

Figure 9. First order plot for the decomposition of $0.2 \mathrm{M}$ cumene hydroperoxide by $0.2 \mathrm{M}$<smiles>[R]P1Oc2ccccc2O1</smiles>

in chlorobenzene at $75 \mathrm{C}$.

The action of the catechol phosphite esters is remarkably similar in many ways to the behaviour of the sulphur-containing peroxide decomposers ${ }^{26}$. Both appear to act by producing powerful Lewis acid catalysts for the decomposition of hydroperoxides. This is shown for the catechol phosphites in Figure 9. And both appear to involve, in the early stages of the autoxidation 


\section{G. SCOTT}

process, an initial radical generating reaction in the presence of hydroperoxide which gives rise to pro-oxidant effects (see Figure 10). Pobedimskii and his co-workers ${ }^{27}$ have postulated on the basis of e.s.r. evidence the

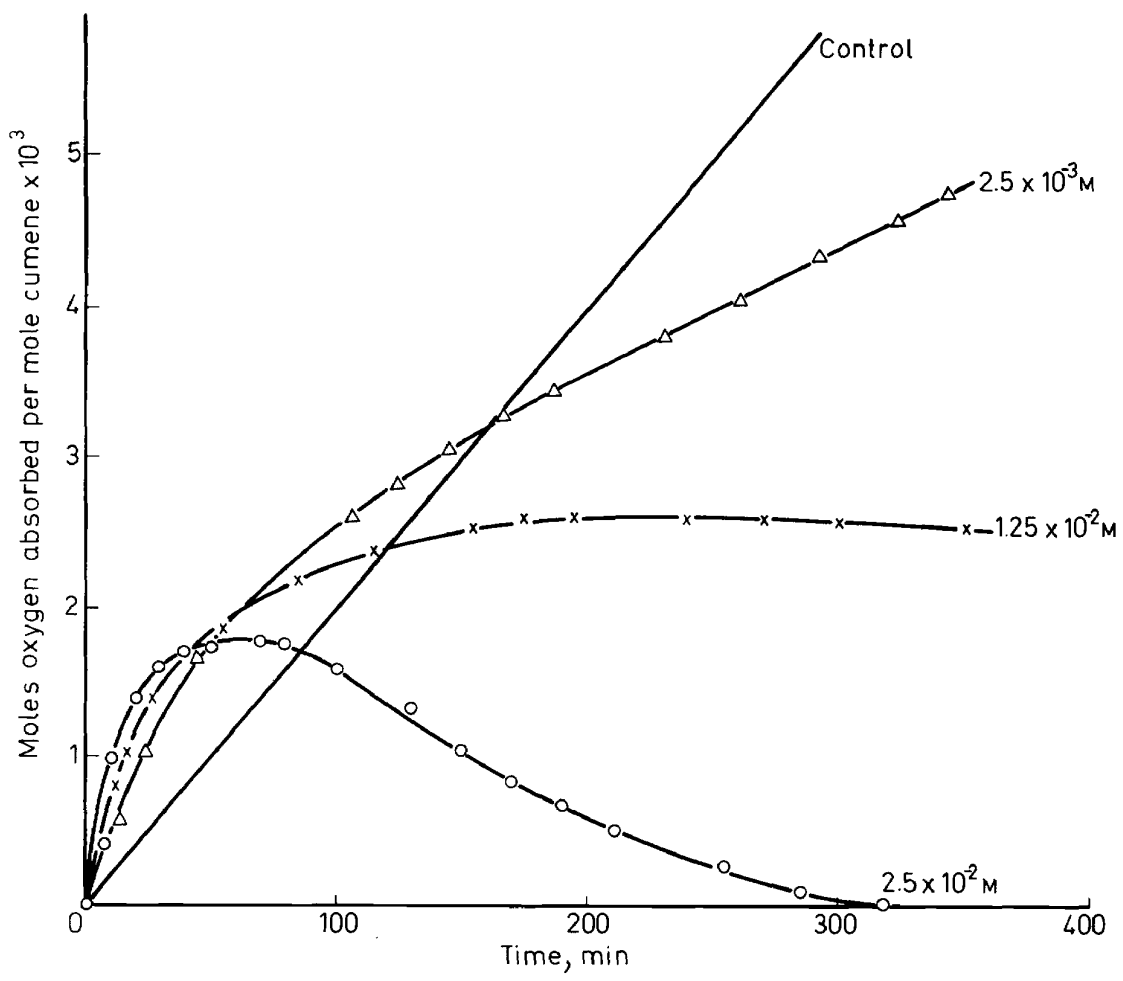

Figure 10.

formation of a radical cage reaction by interaction of the phosphorus compound with hydroperoxide to account for this.

$$
\begin{aligned}
& (\mathrm{RO})_{3} \mathrm{P}+\mathrm{R}^{\prime} \mathrm{OOH} \rightarrow\left[(\mathrm{RO})_{3} \mathrm{P}--\mathrm{O}-\mathrm{R}^{\prime}\right] \\
& \mid \begin{array}{ll}
\mathrm{OH} \\
\\
(\mathrm{RO})_{3} \mathrm{P}=\mathrm{O} \\
\quad+\mathrm{ROH}
\end{array}
\end{aligned}
$$

and a similar reaction with sulphide leading to sulphoxide and alcohol. Pobedimskii ${ }^{27}$ suggests that a small proportion of the radicals escape from the cage. Humphris and Scott ${ }^{26}$ have found considerable support for this mechanism with the catechol phosphite ester (IX) since changing from a 


\section{MECHANISMS OF POLYMER STABILIZATION}

non-polar to a polar solvent, such as nitrobenzene, changes the nature of the products of cumene hydroperoxide decomposition from those which would be expected on the basis of a radical reaction ( $\alpha$-methylstyrene and acetophenone) to those expected on the basis of a Lewis acid catalysed reaction (phenol and cumene). The Lewis acid is formed in a step subsequent to the above reaction.<smiles>Cc1cc([13CH2])c(OP2Oc3ccccc3O2)c([18CH2])c1</smiles>

(IX)

Evidence has been obtained for the participation of free radicals in the reaction between catechol phosphite esters and hydroperoxides not only in observation of pro-oxidant effects but also in enhanced rate of initiation of styrene by this system (Figure 11).

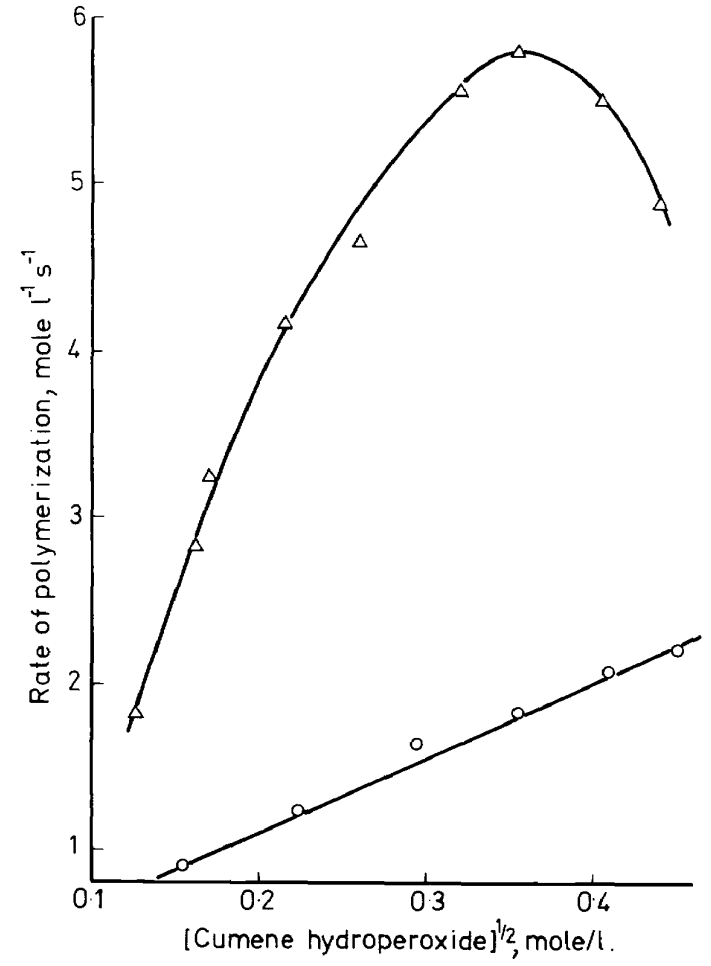

Figure 11. Polymerization of styrene at $75^{\circ} \mathrm{C}$ in air: $\bigcirc$ uninhibited; $\triangle$ with 0.01 mole/l.<smiles>C=C(C)c1cc(C)cc(C(C)(C)C)c1OP1Oc2ccccc2O1</smiles> 


\section{G. SCOTT}

The evidence for Pobedimskii's mechanism is much less unequivocal for the sulphides since in this case, the derived sulphoxide has also been found to be a powerful pro-oxidant with hydroperoxide ${ }^{12}$.

This system has been studied in some detail and it has been found that dimethylsulphinyldipropionate breaks down in a first order reaction to give methyl acrylate. This reaction is reversible particularly in polar solvents (see Table 7) and the products are the expected thiolsulphonates with the formation of the theoretical amount of water and disproportionation products.

Table 7. Yield of methylacrylate from dimethylsulphinyl dipropionate $(0.04 \mathrm{M})$ in the presence and absence of added methylacrylate $(0.04 \mathrm{M})$ at $75^{\circ} \mathrm{C}$ in various solvents.

\begin{tabular}{cccc}
\hline & \multicolumn{3}{c}{ Yield (mole litre $^{-1}$ ) } \\
\cline { 2 - 4 } Solvent & $\begin{array}{c}\text { Carbon } \\
\text { tetrachloride }\end{array}$ & Dioxane & Chlorobenzene \\
\hline With methylacrylate & 0.0375 & 0 & 0 \\
\hline Without methylacrylate & 0.045 & 0.038 & 0.038 \\
\hline
\end{tabular}
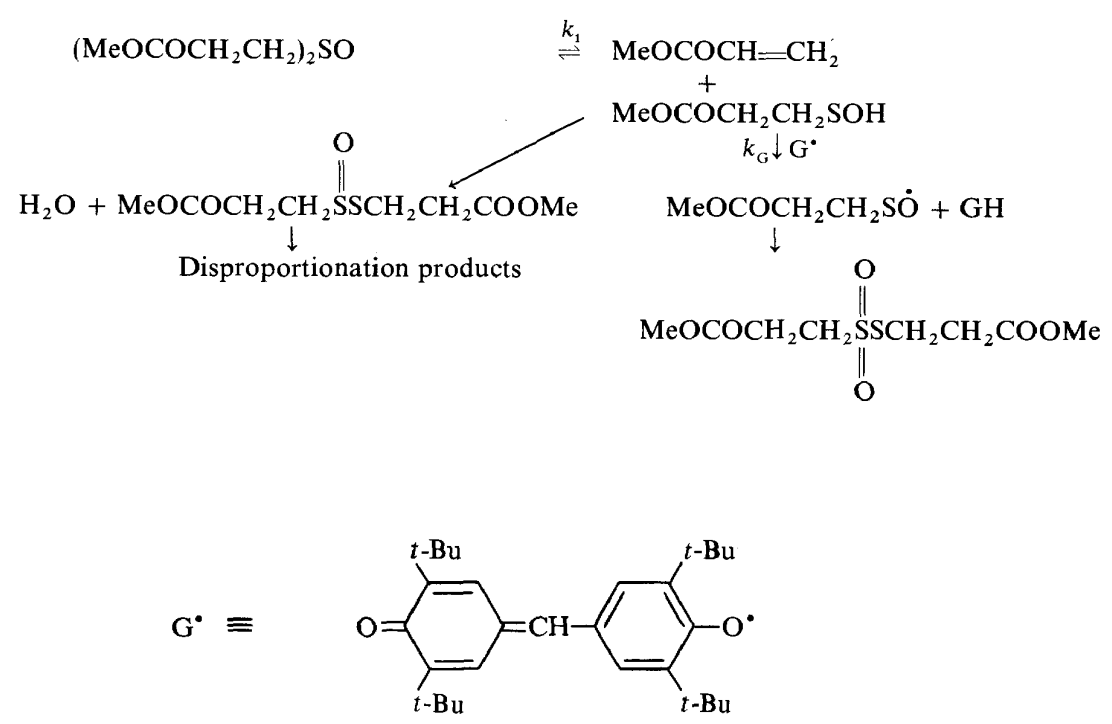

In the presence of the stable free radical galvinoxyl no water is formed and the product is the thiolsulphonate which is more stable than the thiolsulphinate. The first order rate constant for the disappearance of galvinoxyl in carbon tetrachloride measured in an e.s.r. spectrometer is in good accord with that for methylacrylate formation (Table 8 ) considering the reversible 
Table 8. First order rate constants for methylacrylate formation $\left(k_{1}\right)$ and galvinoxyl disappearance $\left(k_{\mathrm{G}}\right)$ in the decomposition of dimethylsulphinyl dipropionate.

\begin{tabular}{ccccccc}
\hline Temperature, ${ }^{\circ} \mathrm{C}$ & 75 & 70 & 65 & 60 & 55 & 50 \\
\hline $10^{5} k_{1}$ & 5.8 & 3.58 & 2.54 & - & 0.73 & 0.54 \\
$10^{5} k_{\mathrm{G}}$ & - & 5.40 & 3.37 & 1.59 & 0.99 & 0.65 \\
\hline
\end{tabular}

nature of this reaction. The activation energies of the two processes are 93 and $101 \mathrm{~kJ} \mathrm{~mol}^{-1}$ respectively.

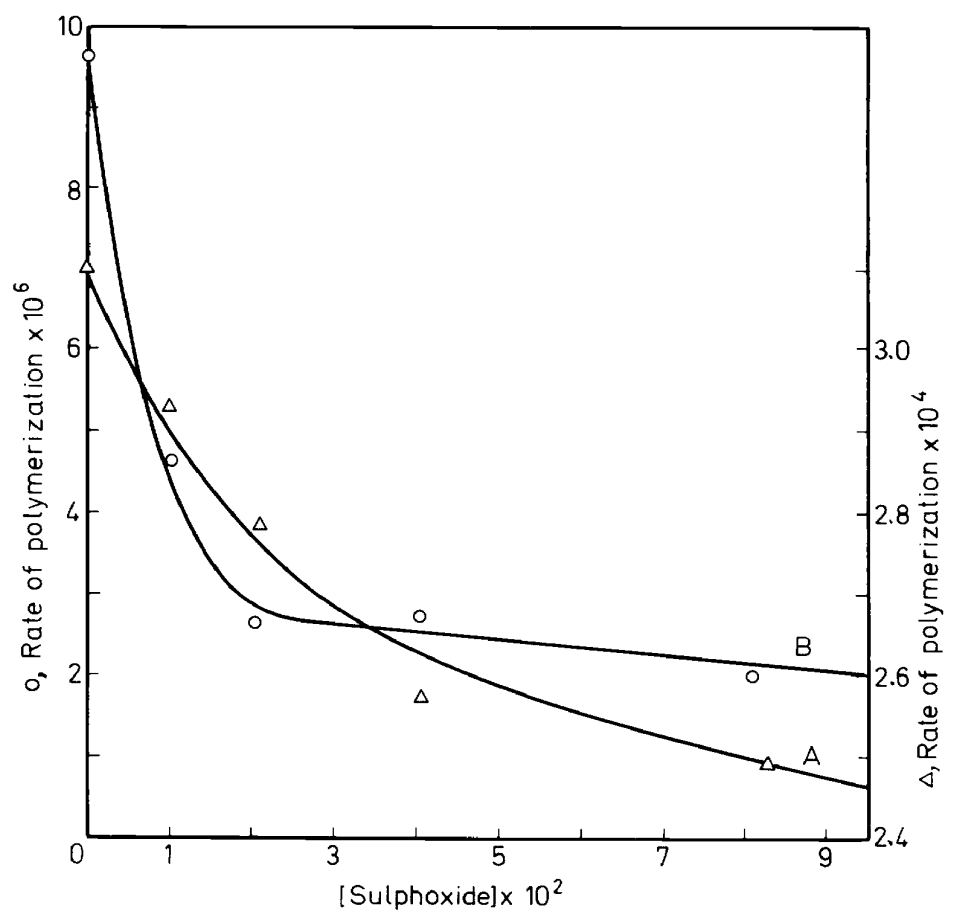

Figure 12. Rate of polymerization of styrene in the presence of dimethylsulphinyl diprepionate

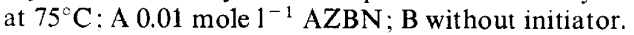

The sulphoxide appears to be an effective retarder for styrene polymerization when initiated by AZBN or purely thermally (see Figure 12). This is almost certainly due to the ability of the sulphenic acid to transfer a hydrogen to a growing polymer radical in competition with the chain propagation step.

It acts both as a retarder and as an activator in the hydroperoxideinitiated polymerization of styrene (see Figure 13) and which process super- 


\section{G. SCOTT}

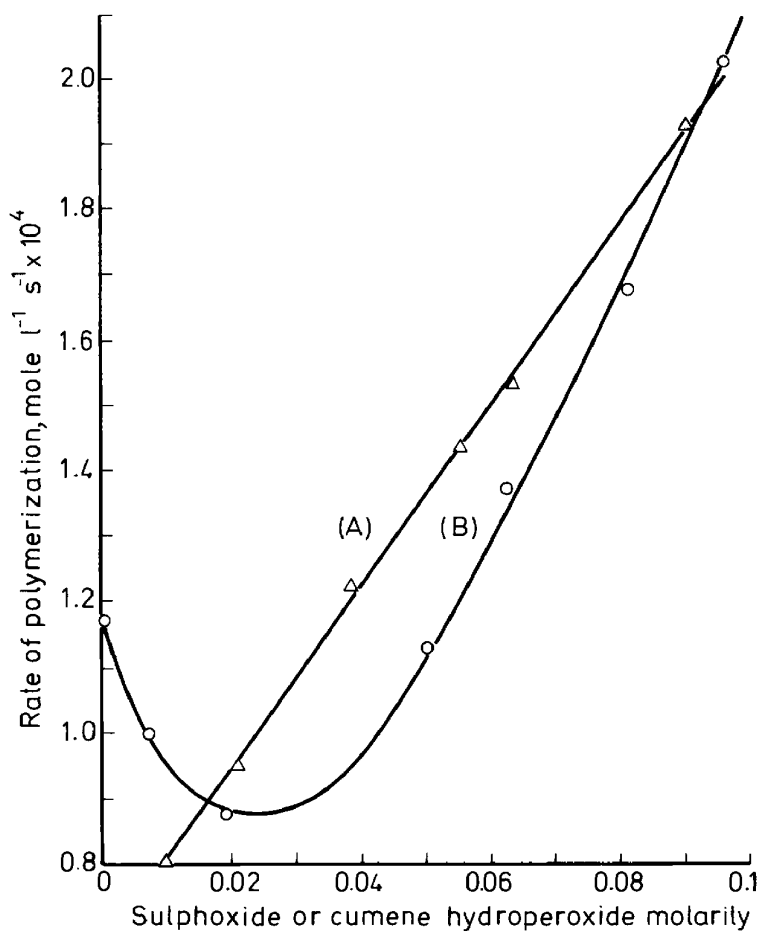

Figure 13. Polymerization of styrene in the presence of both sulphoxide and hydroperoxide in vacuo. A 0.055 mole $1^{-1}$ dimethylsulphinyl dipropionate; B 0.038 mole $1^{-1} \alpha$-cumene hydroperoxide.

venes depends mainly on the ratio of hydroperoxide to sulphur compound. The competing reactions are:

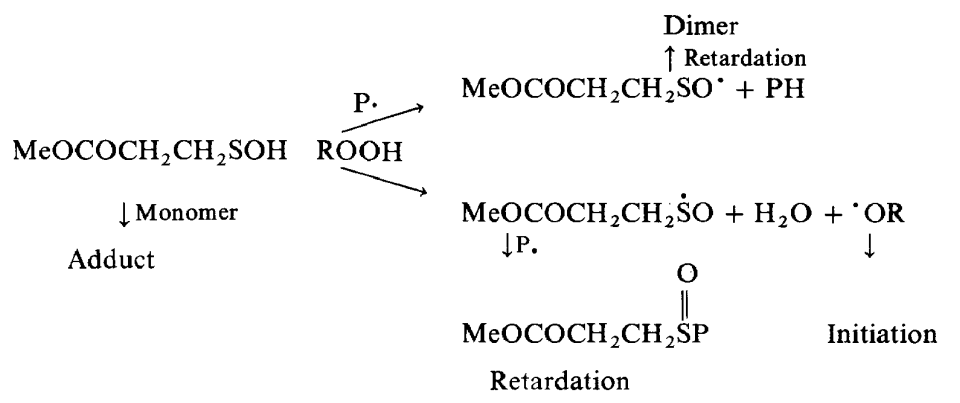

Confirmation for the reaction of sulphenic acid, formed by 5-centre elimination from sulphoxide, has been found in that in a solvent such as dioxane in which the dissociation is reversible, good first order kinetics for methylacrylate formation are obtained in the presence of galvinoxyl. styrene 
and hydroperoxide, all of which react rapidly with the sulphenic acid. As might be expected, the first order rate constants are substantially the same (see Figure 14).

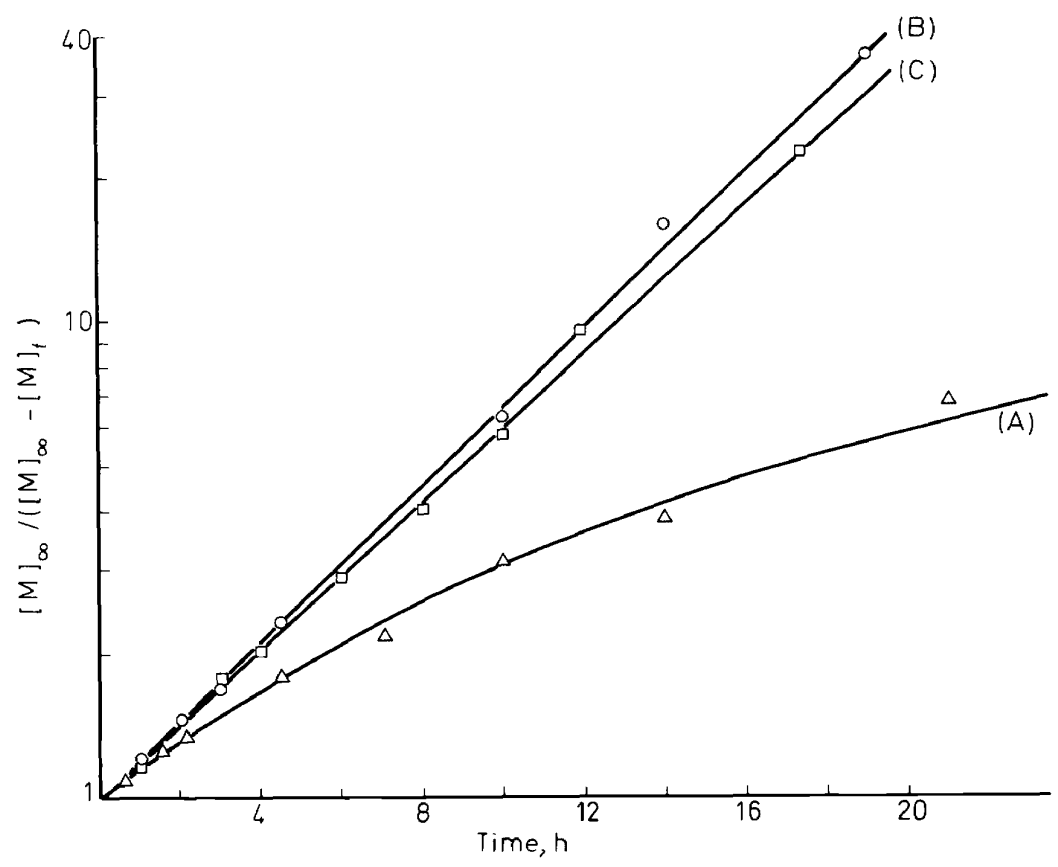

Figure 14. Decomposition of dimethylsulphinyl dipropionate $(0.04 \mathrm{M})$ in dioxane at $75^{\circ} \mathrm{C}$.

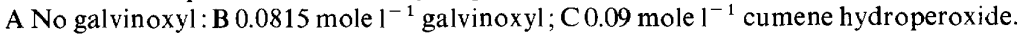

Similar behaviour has been observed in autoxidation. In contrast to the findings of previous workers on the behaviour of sulphoxides in autoxidation. dimethylsulphinyl dipropionate is an effective inhibitor for the AZBNinitiated autoxidation of cumene (Figure 15). In the presence of hydroperoxide, however, a much less unequivocal result is found. At high hydroperoxide to sulphoxide ratios, a strong inhibition is found (see Figure 16). This must be due to a combination of chain-interruptive and peroxidedecomposing mechanisms working together since it has also been shown that the hydroperoxide concentration is rapidly reduced to zero under these conditions ${ }^{14}$. As the amount of sulphoxide is increased in the system, however, radicals are produced as described above and pro-oxidant effects are observed. This gave a satisfactory explanation for the fact that there is a concentration optimum for a thiodipropionate ester acting as a stabilizer in the processing of polypropylene ${ }^{1}$. It also explains why phenolic antioxidants appear to reduce an initial melt degradation which occurs with most sulphur compounds in technological media ${ }^{1,9,13}$. It also seems likely that the reason for the well known auto-retarding curves observed in the autoxidation of 


\section{G. SCOTT}

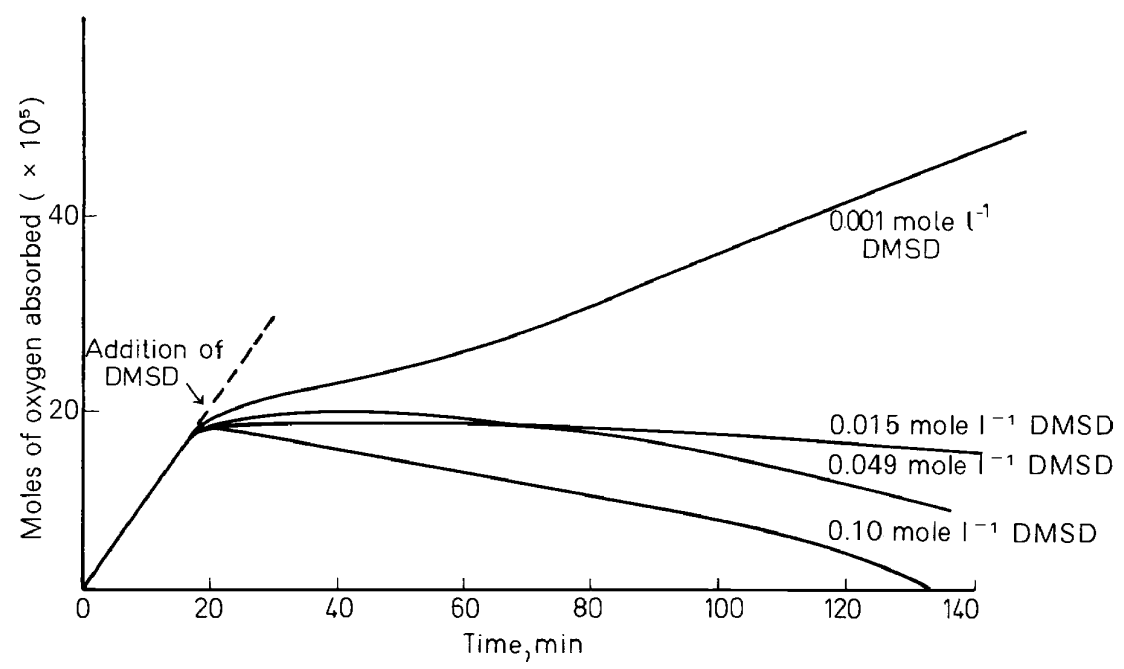

Figure 15 Effect of dimethylsulphinyl dipropionate (DMSD) on the oxidation of cumene initiated with AZBN $(0.00042 \mathrm{M})$ at $75^{\circ} \mathrm{C}$.

most sulphur-vulcanized rubbers is due to the formation and breakdown of sulphoxides to give redox active sulphenic acids. Further work is in progress to establish this.

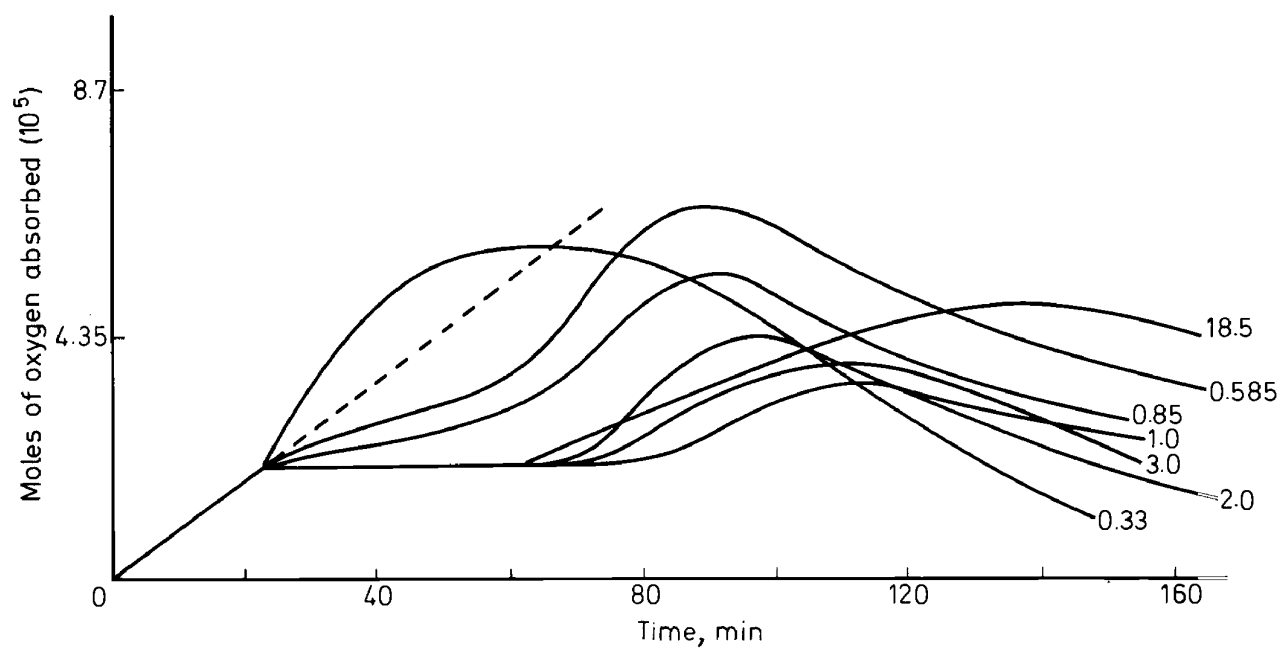

Figure 16. Effect of dimethylsulphinyl dipropionate on the oxidation of cumene initiated by $\alpha$-cumene hydroperoxide $\left(0.05\right.$ mole $\left.1^{-1}\right)$. Temperature $75^{\circ} \mathrm{C}$. Numbers on curves are the ratio [cumene hydroperoxide]/[DMSD]. 


\section{ACKNOWLEDGEMENTS}

I wish to acknowledge my indebtedness to my colleagues who have participated in the studies described in this paper. In particular to Messrs M. A. Plant, C. Armstrong and K. J. Humphris and to Dr W. W. Wright and Mrs G. Knight for providing samples of the polyphenolic antioxidants.

\section{REFERENCES}

1 G. Scott and P. A. Shearn, J. Appl. Polym. Sci. 13, 1329 (1969).

2 J. E. Goodrich, Polym. Engng Sci. 10 (4), 215 (1970).

3 G. Scott, J. Plastics Inst. In press.

4 J. P. Forsman, S.P.E. Journal, 20 (8), 729 (1964).

5 J. W. Tamblyn and G. C. Newland, J. Appl. Polym. Sci. 9, 2251 (1965).

6 D. A. Jorden and E. C. Rothstein, Polym. Engng Sci. 6 (3), 231 (1966).

7 B. Wright, Plastics, 28, 111 (1963).

${ }^{8}$ N. P. Neureiter and D. E. Bown, Industr. Engng Chem. Prod. Res. Develop. 1, 236 (1962).

${ }^{9}$ G. Scott. Europ. Polym. J. (Suppl.), 189 (1969).

10 D. A. Gordon, Advanc. Chem. Ser. 85, 224 (1968).

11 M. A. Plant and G. Scott, Europ. Polym. J. In press.

12 G. Scott, Chem. Commun. 1572 (1968).

13 G. Scott. Mechanisms of Reactions of Sulfur Compounds, 4, 99 (1969).

14 J. D. Holdsworth, G. Scott and D. Williams, J. Chem. Soc. 4692 (1964).

15 C. Armstrong, M. A. Plant and G. Scott, unpublished work.

16 A. F. Lewis and J. K. Gillham, J. Appl. Polym. Sci. 6, 422 (1962); 7, 685 (1963); 7, 2293 (1963).

17 J. K. Gillham, American Chemical Society, Division of Polymer Chemistry, Preprint. 7, 513 (1966); Polym. Engng Sci. 7, 225 (1967).

18 Geigy; Technical Pamphlet, Irganox 1076 (1966).

19 M. A. Plant and G. Scott, unpublished work.

${ }^{20}$ L. N. Phillip, D. K. Thomas and W. W. Wright, Brit. Pat. Appn No. 900/65.

21 Monsanto Lab. Rep. LA25/2 (March 1966).

22 M. E. Cain, G. T. Knight, P. M. Lewis and B. Saville, Rubb. J. 150 (2), 10 (1968).

23 G. Scott, Brit. Polym. J. 3, 24 (1971).

24 P. I. Levin and T. A. Bulgakova, Polym. Sci. USSR, 6, 769 (1964).

25 J. E. Bonkowski, Text. Res. J. 243 (1969).

${ }^{26}$ K. J. Humphris and G. Scott, unpublished work.

27 D. E. Pobedemskii and A. L. Buchachenko, Izvest. Akad. Nauk SSSR, 6, 1181 (1968).

28 C. Armstrong and G. Scott, J. Chem. Soc. In press.

29 D. G. Pobedemskii and A. L. Buchachenko, Izvest. Akad. Nauk SSSR. Chem. Ser.. No. 12, 2750 (1968). 